\title{
Socio-economic status and functional brain development - associations in early infancy
}

Przemyslaw Tomalski ${ }^{* 1,}{ }^{3}$, Derek G. Moore ${ }^{1}$, Helena Ribeiro ${ }^{1,2}$, Emma L. Axelsson ${ }^{1}$, Elizabeth Murphy ${ }^{1}$, Annette Karmiloff-Smith ${ }^{2}$, Mark H. Johnson ${ }^{2}$ and Elena Kushnerenko $* 1$

${ }^{1}$ Institute for Research in Child Development, School of Psychology, University of East London, London, UK

${ }^{2}$ Centre for Brain and Cognitive Development, Department of Psychological Sciences, Birkbeck, University of London, London, UK

${ }^{3}$ Faculty of Psychology, University of Warsaw, Warsaw, Poland

* Corresponding authors: Przemyslaw Tomalski, Faculty of Psychology, University of Warsaw, Poland, Stawki 5/7, 00-183 Warsaw, Poland; e-mail: tomalski@mac.com; Elena Kushnerenko, School of Psychology, University of East London, Water Lane, London E15 4LZ, UK, e-mail: e.kushnerenko@gmail.com

Word count excluding references, figure legends, and tables: 3,891

Acknowledgments. We thank all participating families for their invaluable contribution. We gratefully acknowledge the financial support of Eranda Foundation (PT, MJ \& AK-S), UEL Promising Researcher Grant (EK), UEL School of Psychology (PT \& DM) and UK Medical Research Council G0701484 (MJ). We also thank Martha Farah, Kimberly Noble and two anonymous reviewers for their comments. The EEG resting protocol was developed by MJ and PT. 


\begin{abstract}
Socio-economic status (SES) impacts on both structural and functional brain development in childhood, but how early its effects can be demonstrated is unknown. In this study we measured resting baseline EEG activity in the gamma frequency range in awake 6-9 months-olds from areas of East London with high socio-economic deprivation. Between-subject comparisons of infants from lowand high-income families revealed significantly lower frontal gamma power in infants from low-income homes. Similar power differences were found when comparing infants according to maternal occupation, with lower occupational status groups yielding lower power. Infant sleep, maternal education, length of gestation, and birth weight, as well as smoke exposure and bilingualism, did not explain these differences. Our results show that the effects of socio-economic disparities on brain activity can already be detected in early infancy, potentially pointing to very early risk for language and attention difficulties. This is the first study to reveal region-selective differences in functional brain development associated with early infancy in low-income families.
\end{abstract}




\section{Introduction}

Few studies have investigated the relationship between socio-economic status (SES) and neuro-behavioural functioning in children (e.g. Noble, Norman, \& Farah, 2005; Rao, et al., 2010). These have revealed specific SES effects on language development and executive control (for a review see: Hackman \& Farah, 2009; Hackman, Farah, \& Meaney, 2010; Raizada \& Kishiyama, 2010), indicating that by school age SES may have specific rather than general effect on cognitive and neural systems. In one of the few studies examining neural activity directly, low SES related to lower hemispheric specialization of inferior frontal gyrus in 5-year-olds (Raizada, Richards, Meltzoff, \& Kuhl, 2008). It is yet to be determined whether these specific effects are apparent even earlier, whether they generalise to low-SES samples across countries and are demonstrable using measures of electrical brain activity.

Resting baseline EEG is commonly measured while infants are engaged in observation of general stimuli rather than responses time-locked to specific events. Measuring resting EEG power in specific frequency ranges is useful for studying infant functional brain development and for identifying early risk factors (Marshall, Reeb, Fox, Nelson, \& Zeanah, 2008). Spectral analysis of EEG allows the quantification of oscillatory activity at low (theta, alpha) and high (beta, gamma) frequencies. Although the functional role of high frequency neural oscillations in the gamma range has been less explored, these oscillations are thought to support attentional processes, perceptual binding and maintaining high-level neural representations of objects (e.g. Engel, Fries, \& Singer, 2001). 
Individual differences in power, coherence and hemispheric asymmetry were found in infants and children of depressed mothers (Dawson, Klinger, Panagiotides, Hill, \& Spieker, 1992; Jones, Field, \& Almeida, 2009; Jones, Field, \& Davalos, 2000; Jones, Field, Fox, Lundy, \& Davalos, 1997), infants who experienced institutionalization (Marshall \& Fox, 2004; Marshall, et al., 2008); and children with autism (Orekhova, et al., 2007).

Gamma-band oscillations in infant EEG are usually defined as synchronous electrical brain activity in the 20-60 Hz range (Kaufman, Csibra, \& Johnson, 2005), while a recent study on the robustness of frequency definitions for oscillatory activity in resting EEG proposed a 21-49 Hz range (Shackman, McMenamin, Maxwell, Greischar, \& Davidson, 2010). Atypical induced gammaband activity was identified in visual processing in Williams syndrome (Grice, et al., 2005; Grice, et al., 2001), and delayed over right temporal areas in response to direct gaze in infants at-risk of autism (Elsabbagh, et al., 2009). Benasich and colleagues (2008) demonstrated that individual differences in frontal gammaband activity relate to differences in language and cognitive skills in 16-36 month-olds and that they predict language development at 4-5 years of age (Gou, Choudhury, \& Benasich, 2011). Decreased absolute and relative gamma power in resting EEG was reported for children with Attention-Deficit/Hyperactivity Disorder (ADHD) (Barry, et al., 2010), along with reduced intra-hemispheric coherence at short electrode distances and reduced inter-hemispheric coherence for frontal areas. Symptom severity correlated negatively with left-lateralized electrode coherences (Barry, et al., 2011). Thus, studies of resting EEG in at-risk and clinical populations suggest that symptom severity and risk for later developmental difficulties relate to high-frequency electrical brain activity. 
We investigated the relationship between infant resting brain activity and measures of socio-economic status (SES). The most commonly used measures of SES are family income, maternal education and categories of "social class" based on parental occupation (Duncan \& Magnuson, 2001; Hollingshead, 1975). Using a range of measures is important because, while they are often highly correlated, the strength of these correlations varies according to country and regional characteristics. Our East London sample came from areas of high immigration, high casual labour and low wages, where educational level may be less correlated with income and occupation than in areas where immigration levels are lower. Area-based statistics may also be less predictive of outcomes in highly mixed urban populations where large differences in family circumstances exist within the same street. This contrasts with more 'ghettoised' urban areas where family circumstances are more homogeneous. For these reasons we used family income and parental occupation as our main SES measures.

There are many potential social and biological mechanisms by which SES could impact on infant development: poor parental education, low quality of parental care, impoverished environments, poor diet, poor sleep patterns, prenatal exposure to toxic substances, etc. (Bradley \& Corwyn, 2002). These factors could generate individual differences even by 6-9 months and may be reflected in the amount of high-frequency activity measured in the resting brain.

Given the evidence for the impact of SES on functional brain development in childhood and adolescence, we hypothesised that even by 6-9 months, individual 
differences in resting brain activity may relate to measures of SES, particularly to household income for the East London population. As language development and executive functions are two domains particularly sensitive to adverse environments (see: Bradley \& Corwyn, 2002; Hackman, et al., 2010), we hypothesized that SES-related differences in resting EEG would be indicative of such difficulties already in infancy. Based on previous studies in children with family histories of poor language outcome showing lower gamma power over frontal areas compared with a matched low-risk group (Benasich, et al., 2008) and decreased gamma power in children with poor attention skills (Barry, et al., 2010), we predicted that infants from lower-SES families would show reduced gamma power particularly over frontal areas, reflecting greater language and attention risks even before their first birthday. 


\section{Methods}

\section{Participants}

Participants were recruited from three East London boroughs with high levels of multiple deprivation ${ }^{1}$ (Tower Hamlets, Hackney and Newham), through local GP surgeries, nurseries and community centres. Reflecting the population of this London area, the participants had a wide range of income and education levels, yet all lived with high levels of multiple deprivation (ranked 3-30\% of most deprived areas in England). We excluded infants with major medical conditions, pregnancy complications or premature birth ( $<36$ weeks). No mother reported using recreational drugs while pregnant. Eight infants were excluded due to fussiness $(n=4)$, technical error $(n=2)$, or noisy data $(n=2)$.

Reflecting the mixed ethnic composition of East London, the final sample of 45 infants (31 girls and 14 boys, age $M=226.4$ days, $S D=44.3$, age range $178-300$ days) comprised: 27 Caucasian, 5 African, 4 Asian, 9 mixed, originating from different countries and languages. The study received university and NHS-IRAS ethical approval. All parents gave prior informed consent.

Based on previous findings (Kishiyama, Boyce, Jimenez, Perry, \& Knight, 2009) we noted that the effects of SES may not be continuous or linear and that thresholds may exist above and below which family circumstances have few

\footnotetext{
${ }^{1}$ Multiple deprivation is defined by lack of resources of different kinds experienced by individuals living in one area relative to other areas in the country. The Index of Multiple Deprivation is calculated by the UK Office for National Statistics and encompasses seven domains of deprivation: income, employment, health \& disability, education, skills \& training, barriers to housing and services, crime and living environment (McLennan, et al., 2011).
} 
additional positive or negative effects. If this is so, then correlational analyses may be less sensitive than simple comparisons between lower- and higher-SES groups. Thus, we compared participants based either on median split in gross family income, allocating infants into groups of lower (LI) and higher (HI) SES participants, or on three occupational groups (these were confirmed by regression analyses of continuous variables of gross income and income per family member, and of categorical variable of occupation, see Supporting Results). Occupational groups were determined using current parental occupation, classified according to the Social Occupation Classification (SOC) on a four-category scale (UK Office for National Statistics, 2010) as: (1) higher managerial or professional, (2) intermediate and (3) routine/semi-routine and (4) unemployed over 6 months. For between-subject comparisons, categories 3 and 4 were collapsed. Parental education was not used as an indicator because the population was relatively well educated, reflecting a high proportion of recent immigrants living in poverty (see Supporting Results).

\section{General procedure}

Infants first participated in the EEG recording, followed by an assessment with the Bayley Scales of Infant Development (BSID-II, Bayley, 1993), to obtain mental (MDI) and motor (PDI) scores. Subsequently, a trained researcher conducted an interview with the parent, targeting various demographics. Since the impact of family SES on child outcomes may be moderated by sleep quality (El-Sheikh, Buckhalt, Keller, Cummings, \& Acebo, 2007), we measured infant sleep quality/quantity using the Brief Infant Sleep Questionnaire (Sadeh, 2004). The visit lasted approximately 1.5 hours. 


\section{EEG recording and data analyses}

Infants were seated on their parent's lap in a dimly lit booth $(90 \mathrm{~cm}$ distance from a 19" monitor). A 128-channel Hydrocel sensor net (EGI) was placed on the infant's head. The EEG recording (lasting <15 min.) started first with another cognitive task (not reported here), then with resting EEG videos. Participants were presented with 2-5 video clips (each 45 s-long), one showing colourful toys in motion, one with human faces singing baby rhymes and gesturing. Data from both sequences were combined (see Supporting Methods for control comparisons of stimulus presentation). The rationale for choosing these video clips was to provide infants with typical experiences: toys and interacting faces. Infant behaviour was monitored and recorded for subsequent off-line scoring of EEG artefacts.

EEG signals were acquired with the Electrical Geodesics (EGI Inc.) NetAmps200 amplifier; signal was hardware band-pass filtered $(0.1-100 \mathrm{~Hz})$, referenced to the vertex and digitized at $500 \mathrm{~Hz}$. Continuous EEG recording was segmented into 3s-long epochs, followed by automatic and additional manual artefact rejection, which yielded equal numbers of segments for participants from different SES groups (see Supporting Materials). For the remaining segments, signals in individual bad channels were replaced by interpolation. Timefrequency decomposition was conducted with Fast Fourier Transform (FFT) in the $3-45 \mathrm{~Hz}$ frequency range (1 Hz bins, $0.5 \mathrm{~s}$ Hanning window). Frequencies higher than $45 \mathrm{~Hz}$ were not analysed due to the presence of $50 \mathrm{~Hz}$ mains noise in the signal. Developmental studies have hitherto reported either absolute or relative EEG power, with both measures having advantages and disadvantages 
(Marshall, Bar-Haim, \& Fox, 2002). Here we report absolute power values, since relative power data yielded similar results, as there were no major differences in the low frequency bands across participant groups. Frequency bands of spontaneous oscillatory activity were defined on the basis of previous literature (Marshall \& Fox, 2007), in particular adopting the $21 \mathrm{~Hz}$ cut-off frequency for gamma band in line with a recent study on the robustness of beta and gamma categories (Shackman, et al., 2010). Average power was calculated for theta (3-5 $\mathrm{Hz}$ ), alpha (6-9 Hz), beta (13-19 Hz) and two gamma frequency ranges (21-30 $\mathrm{Hz}, 31-45 \mathrm{~Hz}$ ). Since previous research used different gamma frequency definitions (31-50 Hz, see Benasich, et al., 2008), we opted for splitting this range into two and treating it as a factor in subsequent analyses. The analyses of SES effects for lower frequencies (theta, alpha and beta) were solely conducted for control purposes (see Supplementary Results). Average power values were computed across electrodes in four groups, based on pilot work and previous literature (Benasich, et al., 2008) (see Figure 1): temporal left, temporal right, fronto-central and posterior. The data were entered into repeated-measures mixed-model ANOVAs. Greenhouse-Geisser corrections were used where necessary; significance levels for t-tests were Bonferroni-corrected and reported two-tailed.

_Figure_1_here 


\section{RESULTS}

\section{Socio-economic and demographic characteristics}

Parents were interviewed about a range of demographic and family factors (see Table 1). We allocated participants to income groups based on reported gross annual household income ${ }^{2}$. We calculated this by combining the gross 2-parent income or, where appropriate, the income of a single parent ${ }^{3}$. Income included any unemployment benefits and any regular financial assistance from relatives.

Table_1_here

The average gross income in the LI group was not merely low compared to the comparison group but also low for the UK, with 13 of 22 participants (65\%) below the UK poverty line ${ }^{4}$. Note that the costs of living in London are higher than elsewhere in the UK, making the national poverty line higher for this region, with this group well below even this line.

The groups did not differ in infant gender distribution, ethnicity, gestational age or birthweight. However, the lower- and higher-income groups (LI and HI, respectively) differed significantly in terms of maternal and paternal occupation (SOC), while maternal and paternal education showed a near-significant

\footnotetext{
2 The sample had high variability in average family income, reflecting the populations of the targeted London areas. Average gross household income in the UK (before tax) was $£ 35,620$ in 2009 , but in London as much as $£ 48,880$ (Horsfield, 2010).

${ }^{3}$ In single-parent households the non-residing parent's contribution was added if he/she supported the child financially.

4 The UK Government has set the poverty line at 60\% (Adams, Barton, Bray, Johnson, \& Matejic, 2010) of that income, i.e. for 2009, $£ 21,372$ nationally and $£ 29,328$ in the London area.
} 
difference. Mothers from higher earning families were significantly older (34 vs. 29 years).

\section{Bayley scales}

All infants scored within the normal range (see Table 1), although the LI-group scored lower than the HI-group on the Mental Scale. Note, however, that comparing standardised scores using confidence intervals, the difference between groups fell within the Scale's margin of error.

\section{Sleep}

Given the potential relevance of sleep to resting EEG in the awake state, we interviewed parents about infants' sleep patterns with the Brief Infant Sleep Questionnaire (Sadeh, 2004). This ten-item scale screens for infant and toddler sleep disturbances and targets nocturnal and daytime sleep duration, time of nocturnal wakefulness, number of night wakings, nocturnal sleep-onset time. settling time, preferred sleeping body position, method of soothing and sleeping arrangements. Sleep duration data were re-calculated in minutes for each income group (see Table 2).

_- Table 2_here

No significant differences between the LI- and HI-groups emerged on any sleep duration measures nor number of nocturnal wakings. Infants from both groups revealed remarkably similar nocturnal and daytime sleep patterns. It was only parents' perception of their infant's sleep that resulted in a non-significant trend for HI who less often considered their infant's sleep problematic. 


\section{Associations of gamma-band activity of resting EEG with SES}

Differences by income group. Differences according to income group, using a $2 \times 4$ x 2 mixed-model ANOVA with frequency range (21-30 Hz and 31-45 Hz), and channel groups (frontal, temporal left, temporal right and occipital) as withinsubjects factors and income group (LI vs. HI) as a between-subjects factor (Figure 2) yielded a significant interaction of all factors $(\mathrm{F}(3,129)=3.77, \mathrm{p}=.029$, $\eta_{\mathrm{p}}{ }^{2}=.081$ ), with channel group interaction with income group also approaching significance $\left(F(3,126)=3.09, p=.061, \eta_{p}^{2}=.067\right)$. See Figure $2 A$ for spectral plots for each channel group and Figure 3A for topographic maps of power in both gamma ranges.

We predicted specific SES-related differences in frontal gamma power, as this had previously been related to individual differences in language and attention development (Benasich, et al., 2008). A planned comparison between LI- and HIgroups in frontal gamma power yielded a significant difference in the lower band and a near-significant trend in the higher gamma band $(21-30 \mathrm{~Hz}, \mathrm{~F}(1,43)=4.75$, $\mathrm{p}=.035 ; 31-45 \mathrm{~Hz}, \mathrm{~F}(1,43)=3.23, \mathrm{p}=.072)$. No group differences emerged for other scalp locations (all ps $>.34$ ).

The association between family income and frontal gamma power in both ranges was confirmed in additional regression analyses, using SES measures as a continuous variable $\left(\mathrm{R}^{2}=.239\right.$ and $\mathrm{R}^{2}=.228$, respectively, both $\mathrm{ps}=.002 ; 7$ outliers excluded with family income exceeding 2SD, see Supporting Results). This relationship also proved significant when gross income per family member was considered $\left(\mathrm{R}^{2}=.125, \mathrm{p}=.03\right.$ and $\mathrm{R}^{2}=.104, \mathrm{p}=.049$, respectively).

_Figure_2A_and_2B_here 
Differences by occupational classification (SOC). An analysis based on occupational status (UK Office for National Statistics, 2010) used two three-way ANOVAs: one for mothers, one for fathers (Parental SOC $\mathrm{x}$ channel group $\mathrm{x}$ frequency band). The analysis of maternal SOC (see Figure 3) yielded a significant three-way interaction (channel group $\mathrm{x}$ frequency $\mathrm{x}$ social class, $\left.F(6,126)=2.83, p=.032, \eta_{p}^{2}=.119\right)$. As with income group, this effect was driven primarily by frontal area differences. The effect was significant in the higher gamma band (31-45 Hz, F(2,42)=3.70, p=.034) and approached significance in the lower gamma band $(21-30 \mathrm{~Hz}, \mathrm{~F}(2,42)=2.96, \mathrm{p}=.063)$. Infants of mothers with managerial and professional occupations ( $\mathrm{SOC}=1)$ showed higher frontal power than those of mothers with intermediate and routine jobs or unemployed (SOC=2 and 3), (LSD post-hoc contrasts, 31-45 Hz, both ps<.041; 21-30 Hz, both ps<.081).

Maternal occupation was dummy re-coded for entering into linear regression to verify group comparisons. These analyses proved significant for both gammaband frequency ranges $\left(\mathrm{R}^{2}=.183, p=.029\right.$ and $\mathrm{R}^{2}=.184, p=.028$, respectively; similarly to the income regression analysis, 7 outliers with income exceeding 2SD were excluded, see Supporting Results).

The analogous ANOVA for paternal social class $(n=38)$ revealed no significant interactions of social class with factors of channel group, frequency band or both (all Fs $<0.72$, all ps $>.55$, all $\eta_{p}{ }^{2}<.042$ ).

__Figure_3A_and_3B_here 


\section{Gamma-band resting EEG - other factors}

Additional analyses yielded no significant main effect or interaction with gamma power and SES indicators for gender $\left(F(1,43)=0.002, p=.97, \quad \eta_{p}{ }^{2}<.001\right)$, breastfeeding $\quad\left(F(1,41)=0.148, \quad p=.703, \quad \eta_{p}^{2}=.004\right), \quad$ family bilingualism $\left(F(1,41)=0.91, p=.345, \eta_{p}^{2}=.021\right.$; see also Supporting Information), family history of dyslexia $\left(F(1,41)=0.035, p=.85, \eta_{p}^{2}<.001\right)$ or participant age $(F(1,43)=0.092$, $\mathrm{p}=.75, \eta_{\mathrm{p}}^{2}=.002$ ). Similarly, we found no significant effects or interactions on gamma power of resting EEG of living with smokers $(F(1,42)=.01, p=.92$, $\left.\eta_{\mathrm{p}}{ }^{2}<.001\right)$ or exposure to tobacco smoke $\left(\mathrm{F}(1,42)=.015, \mathrm{p}=.904, \eta_{\mathrm{p}}{ }^{2}<.001\right)$. 


\section{Discussion}

Our study aimed at investigating how differences in resting EEG activity are associated with infants' socio-economic background. We explored differences between infants classified by gross family income and parental occupation. Absolute power of resting EEG in two gamma frequency ranges $(21-30 \mathrm{~Hz}$ and 31-45 Hz) of 6 to 9-month-olds was recorded from four scalp areas: frontal, left and right temporal, and occipital. Both low income and maternal occupation were associated with reduced gamma power only over frontal channels. To our knowledge, this is the first evidence of region-selective differences in brain activity associated with early infancy in low-income families. Note that these differences were neither attributable to infant sleep patterns nor parental educational differences, which in our sample did not differ significantly between low- and high-income groups.

Despite limited research on the functional role of high-frequency resting brain oscillations in infancy, several explanations of our results can be considered. Firstly, individual differences in resting gamma-band activity over frontal areas have already been linked to differences in language and cognitive skills in toddlers (Benasich, et al., 2008). Power in the 31-50 Hz range was significantly correlated with standardised measures of expressive language at 16 months, expressive and receptive language at 24 months, as well as Bayley Scales Mental scores at 36 months. Importantly, infants with a familial risk for language impairment have shown consistently lower gamma power over frontal regions in comparison to controls (Benasich, et al., 2008). In adult studies, intracortical gamma-band oscillations index temporal-occipital parts of the language network during word reading and word repetition (Crone, et al., 2001). These studies 
suggest that resting-state and task-related gamma-band activity may index synchronization in developing language networks. Thus, in infants from low-SES backgrounds, reduced gamma-band activity over frontal areas may be an early indicator of greater subsequent risk for poor language outcomes.

A second potential explanation relates to gamma-band activity as an indicator of selective attention engagement. In adult brains, gamma-band activity increases during performance of cognitive tasks, reflecting increasing task difficulty (Gross \& Gotman, 1999). Intracortical studies report substantial increases in frontal gamma power when adults selectively attend to task-related stimuli, irrespective of modality (Ray, Niebur, Hsiao, Sinai, \& Crone, 2008). Additional evidence comes from children with ADHD, who show no stimulus-specific gamma bursts related to selective attention (Yordanova, Banaschewski, Kolev, Woerner, \& Rothenberger, 2001), with their resting EEG revealing a global reduction of absolute and relative gamma power and reduced frontal coherence, with gamma power negatively correlated with inattentiveness severity (Barry, et al., 2011; Barry, et al., 2010). Decreased gamma-band activity in infants from low-SES families may thus reflect higher risk for subsequent selective attention deficits (Lupien, King, Meaney, \& McEwen, 2001; Welsh, Nix, Blair, Bierman, \& Nelson, 2010), particularly concerning auditory and speech material (D'Angiulli, Herdman, Stapells, \& Hertzman, 2008; Stevens, Lauinger, \& Neville, 2009) and novelty detection (Kishiyama, et al., 2009). Older children from low-SES backgrounds show significantly higher risk for executive function deficits (Farah, et al., 2006; Sarsour, et al., 2011) and are more likely to be diagnosed with ADHD (McArdle, Prosser, \& Kolvin, 2004). Thus, our results with respect to young 
infants may be interpreted as an early indicator of potential developmental difficulties in executive control of attention.

Since we found no evidence for lower sleep quality in low-SES infants, our findings cannot be explained by differences in sleep quality between the LI and HI groups, which seem to contradict several reports revealing poor sleep quality in low-SES families where infants sleep with their parents (Lozoff, Askew, \& Wolf, 1996). However, sleep quality seems to be an independent factor moderating the long-term effects of SES on child development (Bernier, Carlson, Bordeleau, \& Carrier, 2010; El-Sheikh, Hinnant, Kelly, \& Erath, 2010). Moreover, the majority of SES and sleep quality effects on cognitive and health outcomes were demonstrated for school-aged children and adolescents (Buckhalt, ElSheikh, \& Keller, 2007), suggesting that SES-related differences in sleep quality develop over the longer term, being less critical during early infancy.

It is also unlikely that differences in gamma-band power related to family SES are explicable by systematic differences between level of arousal and infant sleepiness. Although decreases in gamma-band activity may reflect changes from awake to sleep states, they are typically coupled with increases in theta- and alpha-band activity (Corsi-Cabrera, Sanchez, del-Rio-Portilla, Villanueva, \& Perez-Garci, 2003). Having tested for low-frequency differences related to SES (see Supporting Information), we found no significant variation of resting activity in low frequencies in relation to any SES indicator. Thus, our results cannot be explained by mere state changes across sleep-wake cycles. By the same token, it is unlikely that our results are rooted in differences in motor activity while recording resting EEG. We performed thorough motor and eye 
movement artefact detection, and rejected portions of the EEG recording based on video-scoring for motor behaviour.

There are many hypothesised developmental mechanisms and pathways by which this difference may have occurred. Our findings suggest that a number of other demographic factors are not associated with gamma power differences. However, not all potential pre- and post-natal factors were measured. SESrelated differences are related to pre-natal maternal stress (Van den Bergh, Mulder, Mennes, \& Glover, 2005), diet and exposure to drugs and toxins. These could be additional causes of early functional differences in brain activity. Other factors should also be considered: epigenetic factors (Sweatt, 2009), quality of home environment, and quality/quantity of early mother-infant interaction (Fouts, Roopnarine, \& Lamb, 2007) that cannot be determined by parental interview. Further work is required to explore these causal factors and to develop adequate models of the causal pathways of atypical development (see: Moore \& George, 2011).

Our study provides for the first time evidence of very early $(<9$ months of age differences in functional brain development related to parental socio-economic status. Our findings yielded significantly lower power of high frequency, gammaband oscillations over frontal scalp areas in infants of parents with low income and disadvantageous occupations. Further research is necessary to determine whether these brain function measures can be used to predict poor infant outcomes later in life. Our research offers the potential of using EEG measures as new screening tools for detecting very early risk of language and attention deficits in socially disadvantaged populations. 


\section{References}

Adams, N., Barton, A., Bray, S., Johnson, G., \& Matejic, P. (2010). Households Below Average Income. An analysis of the income distribution 1994/95 - 2008/09. London: Department for Work and Pensions.

Barry, R. J., Clarke, A. R., Hajos, M., Dupuy, F. E., McCarthy, R., \& Selikowitz, M. (2011). EEG coherence and symptom profiles of children with AttentionDeficit/Hyperactivity Disorder. Clin Neurophysiol.

Barry, R. J., Clarke, A. R., Hajos, M., McCarthy, R., Selikowitz, M., \& Dupuy, F. E. (2010). Resting-state EEG gamma activity in children with attentiondeficit/hyperactivity disorder. Clin Neurophysiol, 121(11), 1871-1877.

Bayley, N. (1993). Manual for the Bayley Scales of Infant Development, 2nd ed. San Antonio, TX: Psychological Corporation.

Benasich, A. A., Gou, Z., Choudhury, N., \& Harris, K. D. (2008). Early cognitive and language skills are linked to resting frontal gamma power across the first 3 years. Behav Brain Res, 195(2), 215-222.

Bernier, A., Carlson, S. M., Bordeleau, S., \& Carrier, J. (2010). Relations between physiological and cognitive regulatory systems: infant sleep regulation and subsequent executive functioning. Child Dev, 81(6), 1739-1752.

Bradley, R. H., \& Corwyn, R. F. (2002). Socioeconomic status and child development. Annu Rev Psychol, 53, 371-399.

Buckhalt, J. A., El-Sheikh, M., \& Keller, P. (2007). Children's sleep and cognitive functioning: race and socioeconomic status as moderators of effects. Child Dev, 78(1), 213-231. 
Corsi-Cabrera, M., Sanchez, A. I., del-Rio-Portilla, Y., Villanueva, Y., \& Perez-Garci, E. (2003). Effect of $38 \mathrm{~h}$ of total sleep deprivation on the waking EEG in women: sex differences. Int J Psychophysiol, 50(3), 213-224.

Crone, N. E., Hao, L., Hart, J., Jr., Boatman, D., Lesser, R. P., Irizarry, R., et al. (2001). Electrocorticographic gamma activity during word production in spoken and sign language. Neurology, 57(11), 2045-2053.

D'Angiulli, A., Herdman, A., Stapells, D., \& Hertzman, C. (2008). Children's eventrelated potentials of auditory selective attention vary with their socioeconomic status. Neuropsychology, 22(3), 293-300.

Dawson, G., Klinger, L. G., Panagiotides, H., Hill, D., \& Spieker, S. (1992). Frontal lobe activity and affective behavior of infants of mothers with depressive symptoms. Child Dev, 63(3), 725-737.

Duncan, G. J., \& Magnuson, K. (2001). Off with Hollinghshead: Socioeconomic Resources, Parenting, and Child Development. In M. H. Bornstein \& R. H. Bradley (Eds.), Socioeconomic Status, parenting, and child development. Mahwah, NJ: Lawrence Erlbaum.

El-Sheikh, M., Buckhalt, J. A., Keller, P. S., Cummings, E. M., \& Acebo, C. (2007). Child emotional insecurity and academic achievement: the role of sleep disruptions. J Fam Psychol, 21(1), 29-38.

El-Sheikh, M., Hinnant, J. B., Kelly, R. J., \& Erath, S. (2010). Maternal psychological control and child internalizing symptoms: vulnerability and protective factors across bioregulatory and ecological domains. J Child Psychol Psychiatry, 51(2), 188-198. 
Elsabbagh, M., Volein, A., Csibra, G., Holmboe, K., Garwood, H., Tucker, L., et al. (2009). Neural correlates of eye gaze processing in the infant broader autism phenotype. Biol Psychiatry, 65(1), 31-38.

Engel, A. K., Fries, P., \& Singer, W. (2001). Dynamic predictions: oscillations and synchrony in top-down processing. Nat Rev Neurosci, 2(10), 704-716.

Farah, M. J., Shera, D. M., Savage, J. H., Betancourt, L., Giannetta, J. M., Brodsky, N. L., et al. (2006). Childhood poverty: specific associations with neurocognitive development. Brain Res, 1110(1), 166-174.

Fouts, H. N., Roopnarine, J. L., \& Lamb, M. E. (2007). Social experiences and daily routines of African American infants in different socioeconomic contexts. J Fam Psychol, 21(4), 655-664.

Gou, Z., Choudhury, N., \& Benasich, A. A. (2011). Resting frontal gamma power at 16, 24 and 36 months predicts individual differences in language and cognition at 4 and 5 years. Behav Brain Res, 220(2), 263-270.

Grice, S. J., Halit, H., Farroni, T., Baron-Cohen, S., Bolton, P., \& Johnson, M. H. (2005). Neural correlates of eye-gaze detection in young children with autism. Cortex, 41(3), 342-353.

Grice, S. J., Spratling, M. W., Karmiloff-Smith, A., Halit, H., Csibra, G., de Haan, M., et al. (2001). Disordered visual processing and oscillatory brain activity in autism and Williams syndrome. Neuroreport, 12(12), 2697-2700.

Gross, D. W., \& Gotman, J. (1999). Correlation of high-frequency oscillations with the sleep-wake cycle and cognitive activity in humans. Neuroscience, 94(4), 1005-1018.

Hackman, D. A., \& Farah, M. J. (2009). Socioeconomic status and the developing brain. Trends Cogn Sci, 13(2), 65-73. 
Hackman, D. A., Farah, M. J., \& Meaney, M. J. (2010). Socioeconomic status and the brain: mechanistic insights from human and animal research. Nat Rev Neurosci, 11(9), 651-659.

Hollingshead, A. B. (1975). Four factor index of social status.Unpublished manuscript.

Horsfield, G. (2010). Family spending. A report on the 2009 Living Costs and Food Survey.

Jones, N. A., Field, T., \& Almeida, A. (2009). Right frontal EEG asymmetry and behavioral inhibition in infants of depressed mothers. Infant Behav Dev, 32(3), 298-304.

Jones, N. A., Field, T., \& Davalos, M. (2000). Right frontal EEG asymmetry and lack of empathy in preschool children of depressed mothers. Child Psychiatry Hum Dev, 30(3), 189-204.

Jones, N. A., Field, T., Fox, N. A., Lundy, B., \& Davalos, M. (1997). EEG activation in 1-month-old infants of depressed mothers. Development and Psychopathology, 9(03), 491-505.

Kaufman, J., Csibra, G., \& Johnson, M. H. (2005). Oscillatory activity in the infant brain reflects object maintenance. Proc Natl Acad Sci U S A, 102(42), 15271-15274.

Kishiyama, M. M., Boyce, W. T., Jimenez, A. M., Perry, L. M., \& Knight, R. T. (2009). Socioeconomic disparities affect prefrontal function in children. J Cogn Neurosci, 21(6), 1106-1115.

Lozoff, B., Askew, G. L., \& Wolf, A. W. (1996). Cosleeping and early childhood sleep problems: effects of ethnicity and socioeconomic status. J Dev Behav Pediatr, 17(1), 9-15. 
Lupien, S. J., King, S., Meaney, M. J., \& McEwen, B. S. (2001). Can poverty get under your skin? Basal cortisol levels and cognitive function in children from low and high socioeconomic status. Dev Psychopathol, 13, 653-676.

Marshall, P. J., Bar-Haim, Y., \& Fox, N. A. (2002). Development of the EEG from 5 months to 4 years of age. Clin Neurophysiol, 113(8), 1199-1208.

Marshall, P. J., \& Fox, N. A. (2004). A comparison of the electroencephalogram between institutionalized and community children in Romania. J Cogn Neurosci, 16(8), 1327-1338.

Marshall, P. J., \& Fox, N. A. (2007). Infant EEG and ERP in relation to social and emotional development. In M. de Haan (Ed.), Infant EEG and event-related potentials (pp. 227-250). Hove and New Yrok: Psychology Press.

Marshall, P. J., Reeb, B. C., Fox, N. A., Nelson, C. A., 3rd, \& Zeanah, C. H. (2008). Effects of early intervention on EEG power and coherence in previously institutionalized children in Romania. Dev Psychopathol, 20(3), 861-880.

McArdle, P., Prosser, J., \& Kolvin, I. (2004). Prevalence of psychiatric disorder: with and without psychosocial impairment. Eur Child Adolesc Psychiatry, $13(6), 347-353$.

McLennan, D., Barnes, H., Noble, M., Davies, J., Garratt, E., \& Dibben, C. (2011). The English Indices of Deprivation 2010: Technical Report.

Moore, D. G., \& George, R. (2011). ACORNS: a tool for the visualisation and modelling of atypical development. J Intellect Disabil Res, 55(10), 956-972.

Noble, K. G., Norman, M. F., \& Farah, M. J. (2005). Neurocognitive correlates of socioeconomic status in kindergarten children. Dev Sci, 8(1), 74-87. 
Orekhova, E. V., Stroganova, T. A., Nygren, G., Tsetlin, M. M., Posikera, I. N., Gillberg, C., et al. (2007). Excess of high frequency electroencephalogram oscillations in boys with autism. Biol Psychiatry, 62(9), 1022-1029.

Raizada, R. D. S., \& Kishiyama, M. M. (2010). Effects of socioeconomic status on brain development, and how cognitive neuroscience may contribute to leveling the playing field. [Review]. Frontiers in Human Neuroscience, 4, 12.

Raizada, R. D. S., Richards, T. L., Meltzoff, A., \& Kuhl, P. K. (2008). Socioeconomic status predicts hemispheric specialisation of the left inferior frontal gyrus in young children. Neuroimage, 40(3), 1392-1401.

Rao, H., Betancourt, L., Giannetta, J. M., Brodsky, N. L., Korczykowski, M., Avants, B. B., et al. (2010). Early parental care is important for hippocampal maturation: evidence from brain morphology in humans. Neuroimage, 49(1), 1144-1150.

Ray, S., Niebur, E., Hsiao, S. S., Sinai, A., \& Crone, N. E. (2008). High-frequency gamma activity $(80-150 \mathrm{~Hz})$ is increased in human cortex during selective attention. Clin Neurophysiol, 119(1), 116-133.

Sadeh, A. (2004). A Brief Screening Questionnaire for Infant Sleep Problems: Validation and Findings for an Internet Sample. Pediatrics, 113(6), e570577.

Sarsour, K., Sheridan, M., Jutte, D., Nuru-Jeter, A., Hinshaw, S., \& Boyce, W. T. (2011). Family Socioeconomic Status and Child Executive Functions: The Roles of Language, Home Environment, and Single Parenthood. Journal of the International Neuropsychological Society, 17(1), 120-132. 
Shackman, A. J., McMenamin, B. W., Maxwell, J. S., Greischar, L. L., \& Davidson, R. J. (2010). Identifying robust and sensitive frequency bands for interrogating neural oscillations. Neuroimage, 51(4), 1319-1333.

Stevens, C., Lauinger, B., \& Neville, H. (2009). Differences in the neural mechanisms of selective attention in children from different socioeconomic backgrounds: an event-related brain potential study. Dev Sci, 12(4), 634-646.

Sweatt, J. D. (2009). Experience-Dependent Epigenetic Modifications in the Central Nervous System. Biological Psychiatry, 65(3), 191-197.

UK Office for National Statistics. (2010). Standard Occupational Classification 2010. Volume 3: The National Statistics Socio-economic Classification User Manual. Basingstoke: Palgrave Macmillan.

Van den Bergh, B. R., Mulder, E. J., Mennes, M., \& Glover, V. (2005). Antenatal maternal anxiety and stress and the neurobehavioural development of the fetus and child: links and possible mechanisms. A review. Neurosci Biobehav Rev, 29(2), 237-258.

Welsh, J. A., Nix, R. L., Blair, C., Bierman, K. L., \& Nelson, K. E. (2010). The Development of Cognitive Skills and Gains in Academic School Readiness for Children from Low-Income Families. J Educ Psychol, 102(1), 43-53.

Yordanova, J., Banaschewski, T., Kolev, V., Woerner, W., \& Rothenberger, A. (2001). Abnormal early stages of task stimulus processing in children with attention-deficit hyperactivity disorder--evidence from eventrelated gamma oscillations. Clin Neurophysiol, 112(6), 1096-1108. 


\section{Table legends}

Table 1. Means for sample demographic data, together with participants split into low- and high-income groups (SD in brackets), with values of independent samples t-test (two-tailed) or chi-square likelihood ratio, where relevant. $\mathrm{P}$ values in italics, and in bold where significant.

Parental education: (1) - post-graduate; (2) - higher education degree; (3) further education; (4) - high school A-levels; (5) - GCSE; (6) no qualification. Parental SOC classification: (1) - higher managerial and professional occupations; (2) - intermediate occupations; (3) - routine and manual occupations or long-term unemployed; additional category for fathers: (4) parent not contributing financially and not residing with the child.

Table 2. Infant sleep quality data measured by BISQ for the low- and high-income groups and overall averages, sleep time in minutes, SD in brackets. Data for one participant missing $(n=44)$. 
Table 1

\begin{tabular}{|c|c|c|c|c|c|}
\hline Measure & & $\begin{array}{l}\text { Low- } \\
\text { Income } \\
(n=23)\end{array}$ & $\begin{array}{l}\text { High- } \\
\text { Income } \\
(\mathrm{n}=22)\end{array}$ & $\begin{array}{l}\text { Overall } \\
(n=45)\end{array}$ & $\begin{array}{c}\text { Test } \\
\text { statistic }\end{array}$ \\
\hline $\begin{array}{l}\text { Average gross } \\
\text { household } \\
\text { income }(€)\end{array}$ & & $\begin{array}{l}22,041 \\
(15,320)\end{array}$ & $\begin{array}{l}85,854 \\
(41,981)\end{array}$ & $\begin{array}{l}53,238 \\
(44,712)\end{array}$ & $\begin{array}{l}t=6.72 \\
p<.001\end{array}$ \\
\hline $\begin{array}{l}\text { Average gross } \\
\text { income per } \\
\text { family member } \\
(£)\end{array}$ & & $\begin{array}{l}7,041 \\
(5,422)\end{array}$ & $\begin{array}{l}27,181 \\
(13,979)\end{array}$ & $\begin{array}{l}16,887 \\
(14,548)\end{array}$ & $\begin{array}{l}t=6.32 \\
p<.001\end{array}$ \\
\hline Age (days) & & $\begin{array}{l}230.2 \\
(46.8)\end{array}$ & $\begin{array}{l}222.3 \\
(42.3)\end{array}$ & $\begin{array}{l}226.4 \\
(44.3)\end{array}$ & $\begin{array}{l}\mathrm{t}=0.60 \\
p=.55\end{array}$ \\
\hline Gender & $\begin{array}{l}\text { Female } \\
\text { Male }\end{array}$ & $\begin{array}{l}15 \\
8\end{array}$ & $\begin{array}{l}16 \\
6\end{array}$ & $\begin{array}{l}31 \\
14\end{array}$ & $\begin{array}{l}\mathrm{L} \chi^{2}=0.30 \\
p=.57\end{array}$ \\
\hline Ethnicity & $\begin{array}{l}\text { Caucasian } \\
\text { African } \\
\text { Asian } \\
\text { Mixed/Other }\end{array}$ & $\begin{array}{l}10 \\
4 \\
2 \\
7\end{array}$ & $\begin{array}{l}17 \\
1 \\
2 \\
2\end{array}$ & $\begin{array}{l}27 \\
5 \\
4 \\
9\end{array}$ & $\begin{array}{l}\mathrm{L} \chi^{2}=6.68 \\
p=.083\end{array}$ \\
\hline Gestational age & & $\begin{array}{l}39.6 \\
(2.0)\end{array}$ & $\begin{array}{l}39.6 \\
(1.9)\end{array}$ & $\begin{array}{l}39.6 \\
(1.9)\end{array}$ & $\begin{array}{l}\mathrm{t}=0.03 \\
p=.98\end{array}$ \\
\hline Birth weight & & $\begin{array}{l}3220.4 \\
(638.0)\end{array}$ & $\begin{array}{l}3520.8 \\
(456.9)\end{array}$ & $\begin{array}{l}3374.0 \\
(566.8)\end{array}$ & $\begin{array}{l}\mathrm{t}=1.78 \\
p=.083\end{array}$ \\
\hline $\begin{array}{l}\text { Mother's age at } \\
\text { birth }\end{array}$ & & $\begin{array}{l}29.5 \\
(6.6)\end{array}$ & $\begin{array}{l}34.1 \\
(4.0)\end{array}$ & $\begin{array}{l}31.7 \\
(5.9)\end{array}$ & $\begin{array}{l}t=2.79 \\
p=.008\end{array}$ \\
\hline Mother SOC & $\begin{array}{l}(1) \\
(2) \\
(3)\end{array}$ & $\begin{array}{l}13.0 \% \\
26.1 \% \\
60.9 \%\end{array}$ & $\begin{array}{l}72.7 \% \\
13.6 \% \\
13.6 \%\end{array}$ & $\begin{array}{l}42.2 \% \\
20.0 \% \\
37.8 \%\end{array}$ & $\begin{array}{l}\mathrm{L} \chi^{2}=18.49 \\
p<.001\end{array}$ \\
\hline Father SOC & $\begin{array}{l}(1) \\
(2) \\
(3) \\
(4)\end{array}$ & $\begin{array}{l}34.8 \% \\
21.7 \% \\
17.4 \% \\
26.1 \%\end{array}$ & $\begin{array}{r}63.6 \% \\
4.5 \% \\
27.3 \% \\
4.5 \%\end{array}$ & $\begin{array}{l}48.9 \% \\
13.3 \% \\
22.2 \% \\
15.6 \%\end{array}$ & $\begin{array}{l}\mathrm{L} \chi^{2}=8.91 \\
p=.03\end{array}$ \\
\hline $\begin{array}{l}\text { Mother's } \\
\text { education level }\end{array}$ & $\begin{array}{l}(1) \\
(2) \\
(3) \\
(4) \\
(5) \\
(6)\end{array}$ & $\begin{array}{r}26.1 \% \\
30.4 \% \\
13.0 \% \\
17.4 \% \\
4.3 \% \\
8.7 \%\end{array}$ & $\begin{array}{l}63.6 \% \\
22.7 \% \\
0 \\
9.1 \% \\
4.5 \% \\
0\end{array}$ & $\begin{array}{r}44.4 \% \\
26.6 \% \\
6.6 \% \\
13.3 \% \\
4.5 \% \\
4.5 \%\end{array}$ & $\begin{array}{l}\mathrm{L} \chi^{2}=11.22 \\
p=.082\end{array}$ \\
\hline $\begin{array}{l}\text { Father's } \\
\text { education level }\end{array}$ & $\begin{array}{l}(1) \\
(2) \\
(3) \\
(4) \\
(5) \\
(6)\end{array}$ & $\begin{array}{r}34.8 \% \\
8.7 \% \\
13.0 \% \\
8.7 \% \\
21.7 \% \\
13.0 \%\end{array}$ & $\begin{array}{c}45.5 \% \\
18.2 \% \\
9.1 \% \\
22.7 \% \\
4.5 \% \\
0\end{array}$ & $\begin{array}{r}40.0 \% \\
13.3 \% \\
11.1 \% \\
15.6 \% \\
13.3 \% \\
6.7 \%\end{array}$ & $\begin{array}{l}\mathrm{L} \chi^{2}=9.48 \\
p=.091\end{array}$ \\
\hline $\begin{array}{l}\text { English is first } \\
\text { language? }\end{array}$ & $\begin{array}{l}\text { Yes } \\
\text { No }\end{array}$ & $\begin{array}{l}69.6 \% \\
30.4 \%\end{array}$ & $\begin{array}{l}86.4 \% \\
13.6 \%\end{array}$ & $\begin{array}{l}77.8 \% \\
22.2 \%\end{array}$ & $\begin{array}{l}\mathrm{L} \chi^{2}=1.88 \\
p=.17\end{array}$ \\
\hline $\begin{array}{l}\text { Bilingual } \\
\text { family? }\end{array}$ & $\begin{array}{l}\text { Yes } \\
\text { No }\end{array}$ & $\begin{array}{l}30.4 \% \\
69.6 \%\end{array}$ & $\begin{array}{l}18.2 \% \\
81.8 \%\end{array}$ & $\begin{array}{l}24.4 \% \\
75.6 \%\end{array}$ & $\begin{array}{l}\mathrm{L} \chi^{2}=0.924 \\
p=.34\end{array}$ \\
\hline $\begin{array}{l}\text { Family history } \\
\text { of dyslexia? }\end{array}$ & $\begin{array}{l}\text { Yes } \\
\text { No }\end{array}$ & $\begin{array}{l}0 \% \\
100 \%\end{array}$ & $\begin{array}{l}18.2 \% \\
81.8 \%\end{array}$ & $\begin{array}{l}88.9 \% \\
91.1 \%\end{array}$ & $\begin{array}{l}\mathrm{L} \chi^{2}=6.13 \\
p=.013\end{array}$ \\
\hline Residence & $\begin{array}{l}\text { Own house/flat } \\
\text { Rented house/flat } \\
\text { Rented room } \\
\text { Other }\end{array}$ & $\begin{array}{c}34.8 \% \\
56.6 \% \\
4.3 \% \\
4.3 \%\end{array}$ & $\begin{array}{l}91 \% \\
9 \% \\
0 \\
0\end{array}$ & $\begin{array}{l}62.3 \% \\
33.3 \% \\
2.2 \% \\
2.2 \%\end{array}$ & $\begin{array}{l}\mathrm{L} \chi^{2}=17.08 \\
p=.001\end{array}$ \\
\hline
\end{tabular}




\begin{tabular}{|c|c|c|c|c|c|}
\hline $\begin{array}{l}\text { No of older } \\
\text { siblings }\end{array}$ & $\begin{array}{l}0 \\
1 \\
2 \\
3\end{array}$ & $\begin{array}{l}13 \\
7 \\
1 \\
1\end{array}$ & $\begin{array}{l}13 \\
6 \\
0 \\
0\end{array}$ & $\begin{array}{l}26 \\
13 \\
1 \\
1\end{array}$ & $\begin{array}{l}\mathrm{L} \chi^{2}=2.63 \\
p=.45\end{array}$ \\
\hline $\begin{array}{l}\text { Infant living } \\
\text { with a smoker? }\end{array}$ & Yes & $21.8 \%$ & $0 \%$ & $11.1 \%$ & $\begin{array}{l}L \chi^{2}=7.31 \\
p=.007\end{array}$ \\
\hline $\begin{array}{l}\text { Infant ever } \\
\text { exposed to } \\
\text { tobacco? }\end{array}$ & Yes & $0 \%$ & $4.5 \%$ & $2.2 \%$ & $\begin{array}{l}\mathrm{L} \chi^{2}=1.46 \\
p=.23\end{array}$ \\
\hline $\begin{array}{l}\text { How much the } \\
\text { mother drinks } \\
\text { currently? }\end{array}$ & UK units per week & $\begin{array}{l}1.65 \\
(4.32)\end{array}$ & $\begin{array}{l}1.94 \\
(4.31)\end{array}$ & $\begin{array}{l}1.80 \\
(4.32)\end{array}$ & $\begin{array}{l}\mathrm{t}=0.23 \\
p=.82\end{array}$ \\
\hline Bayley MDI & & $\begin{array}{l}98.5 \\
(7.6)\end{array}$ & $\begin{array}{l}102.9 \\
(5.1)\end{array}$ & $\begin{array}{l}100.8 \\
(6.8)\end{array}$ & $\begin{array}{l}t=2.2 \\
p=.034\end{array}$ \\
\hline Bayley PDI & & $\begin{array}{l}100.3 \\
(9.7)\end{array}$ & $\begin{array}{l}100.1 \\
(10.5)\end{array}$ & $\begin{array}{l}100.2 \\
(10.0)\end{array}$ & $\begin{array}{l}\mathrm{t}=0.064 \\
p=.95\end{array}$ \\
\hline
\end{tabular}




\section{Table 2}

\begin{tabular}{|c|c|c|c|c|c|}
\hline Measure & & $\begin{array}{l}\text { Low- } \\
\text { Income } \\
(n=22)\end{array}$ & $\begin{array}{l}\text { High- } \\
\text { Income } \\
(n=22)\end{array}$ & $\begin{array}{l}\text { Overall } \\
(n=44)\end{array}$ & $\begin{array}{c}\text { Test } \\
\text { statistic }\end{array}$ \\
\hline $\begin{array}{l}\text { Number of night } \\
\text { wakings }\end{array}$ & \multirow{13}{*}{$\begin{array}{l}\text { Crib-sep room } \\
\text { Crib-parent room } \\
\text { Parent's bed } \\
\text { Crib-room with sib } \\
\text { Other } \\
\text { On belly }\end{array}$} & $\begin{array}{l}1.23 \\
(1.4)\end{array}$ & $\begin{array}{l}1.48 \\
(1.1)\end{array}$ & $\begin{array}{l}1.35 \\
(1.2)\end{array}$ & $\begin{array}{l}\mathrm{t}=0.69 \\
p=.49\end{array}$ \\
\hline $\begin{array}{l}\text { Nocturnal sleep } \\
\text { duration }\end{array}$ & & $\begin{array}{l}595.9 \\
(63.0)\end{array}$ & $\begin{array}{l}605.5 \\
(71.5)\end{array}$ & $\begin{array}{l}600.7 \\
(66.8)\end{array}$ & $\begin{array}{l}\mathrm{t}=0.47 \\
p=.64\end{array}$ \\
\hline $\begin{array}{l}\text { Daytime sleep } \\
\text { duration }\end{array}$ & & $\begin{array}{l}137.7 \\
(84.2)\end{array}$ & $\begin{array}{l}148.4 \\
(65.4)\end{array}$ & $\begin{array}{l}143.1 \\
(74.7)\end{array}$ & $\begin{array}{l}\mathrm{t}=0.47 \\
p=.64\end{array}$ \\
\hline $\begin{array}{l}\text { Nocturnal } \\
\text { wakefulness }\end{array}$ & & $\begin{array}{l}23.3 \\
(32.5)\end{array}$ & $\begin{array}{l}27.7 \\
(29.8)\end{array}$ & $\begin{array}{l}25.5 \\
(30.9)\end{array}$ & $\begin{array}{l}\mathrm{t}=0.47 \\
p=.63\end{array}$ \\
\hline $\begin{array}{l}\text { Total sleep } \\
\text { duration }\end{array}$ & & $\begin{array}{l}733.64 \\
(122.0)\end{array}$ & $\begin{array}{l}753.9 \\
(83.5)\end{array}$ & $\begin{array}{l}743.8 \\
(103.8)\end{array}$ & $\begin{array}{l}\mathrm{t}=0.64 \\
p=.53\end{array}$ \\
\hline Settling time & & $\begin{array}{l}28.7 \\
(32.7)\end{array}$ & $\begin{array}{l}30.5 \\
(26.7)\end{array}$ & $\begin{array}{l}29.6 \\
(29.1)\end{array}$ & $\begin{array}{l}\mathrm{t}=0.04 \\
p=.97\end{array}$ \\
\hline Sleep-onset time & & $\begin{array}{l}500.0 \\
(75.4)\end{array}$ & $\begin{array}{l}498.4 \\
(75.0)\end{array}$ & $\begin{array}{l}499.1 \\
(74.3)\end{array}$ & $\begin{array}{l}\mathrm{t}=0.6 \\
p=.95\end{array}$ \\
\hline \multirow{5}{*}{$\begin{array}{l}\text { Infant sleeping } \\
\text { arrangements }\end{array}$} & & $18.2 \%$ & $40.9 \%$ & $29.5 \%$ & \multirow{5}{*}{$\begin{array}{l}\mathrm{L} \chi^{2}=5.34 \\
p=.25\end{array}$} \\
\hline & & $45.4 \%$ & $18.2 \%$ & $31.8 \%$ & \\
\hline & & $13.6 \%$ & $22.7 \%$ & $18.2 \%$ & \\
\hline & & $9.1 \%$ & $9.1 \%$ & $9.1 \%$ & \\
\hline & & $13.6 \%$ & $9.1 \%$ & $11.4 \%$ & \\
\hline \multirow{3}{*}{$\begin{array}{l}\text { Preferred body } \\
\text { position }\end{array}$} & & $31.8 \%$ & $31.8 \%$ & $31.8 \%$ & \multirow{3}{*}{$\begin{array}{l}\mathrm{L} \chi^{2}=0.6 \\
p=.74\end{array}$} \\
\hline & On side & $18.2 \%$ & $27.3 \%$ & $22.7 \%$ & \\
\hline & On back & $50.0 \%$ & $40.9 \%$ & $45.5 \%$ & \\
\hline \multirow{6}{*}{$\begin{array}{l}\text { Method of falling } \\
\text { asleep }\end{array}$} & \multirow{6}{*}{$\begin{array}{l}\text { While feeding } \\
\text { Being rocked } \\
\text { Being held } \\
\text { Bed alone } \\
\text { Bed near parent } \\
\text { Other }\end{array}$} & $50.0 \%$ & $45.5 \%$ & $47.7 \%$ & \multirow{6}{*}{$\begin{array}{l}\mathrm{L} \chi^{2}=6.34 \\
p=.28\end{array}$} \\
\hline & & $4.5 \%$ & 0 & $2.3 \%$ & \\
\hline & & $9.1 \%$ & $13.6 \%$ & $11.4 \%$ & \\
\hline & & $22.7 \%$ & $22.7 \%$ & $22.7 \%$ & \\
\hline & & $9.1 \%$ & 0 & $4.5 \%$ & \\
\hline & & $4.5 \%$ & $18.2 \%$ & $11.4 \%$ & \\
\hline \multirow{3}{*}{$\begin{array}{l}\text { Do you consider } \\
\text { your child's sleep a } \\
\text { problem? }\end{array}$} & Not at all & $81.8 \%$ & $59.1 \%$ & $70.5 \%$ & \multirow{3}{*}{$\begin{array}{l}\mathrm{L} \chi^{2}=2.78 \\
p=.095\end{array}$} \\
\hline & A small problem & $18.2 \%$ & $40.9 \%$ & $29.5 \%$ & \\
\hline & Other responses & 0 & 0 & 0 & \\
\hline
\end{tabular}




\section{Figure legends}

Figure 1. Channel groups of 128-channel Hydrocel EGI net layout used in the resting EEG analysis: fronto-central, posterior, temporal left and right.

Figure 2. Spectral plots of resting EEG with participants split by median gross annual family income (panel A) and maternal occupation, SOC (panel B) for four scalp regions: temporal left and right, frontal and posterior.

Figure 3. Topographic scalp maps representing gamma power of resting EEG in two frequency ranges $(21-30 \mathrm{~Hz}$ and $31-45 \mathrm{~Hz})$ for participants split by gross family income (panel A) and maternal occupation (SOC, panel B). Top scalp projection. 
Figure 1

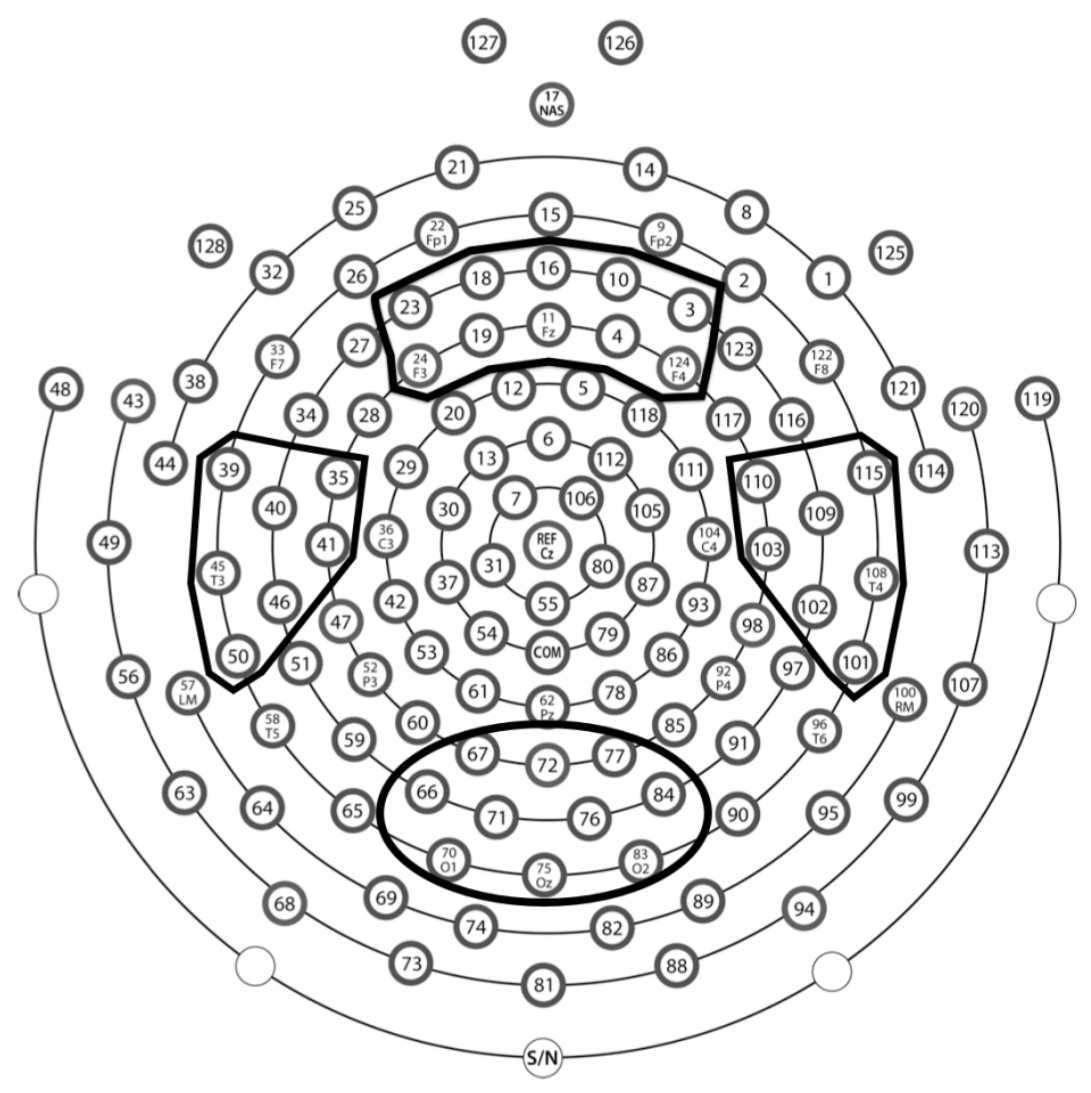


Figure 2A
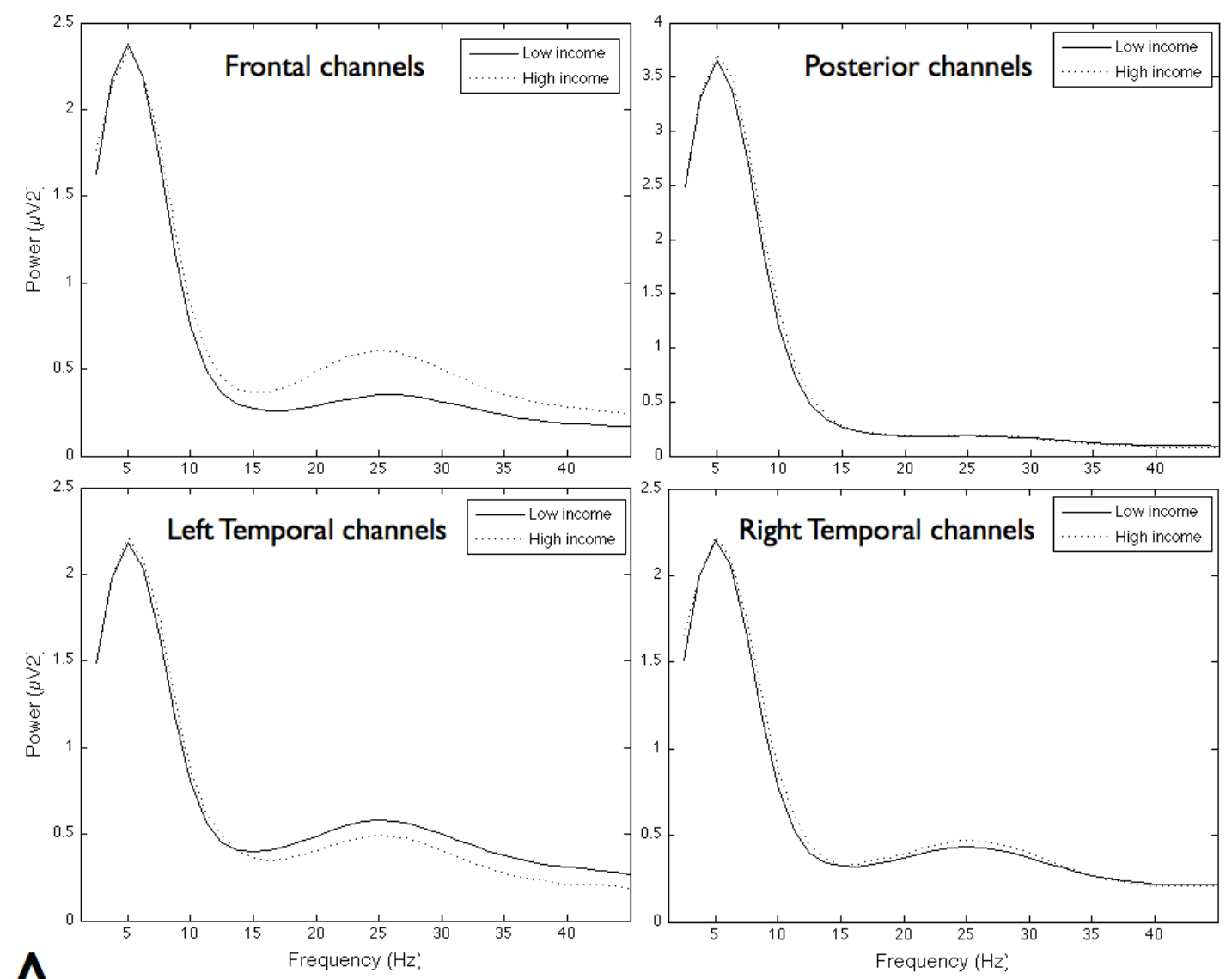

A. 


\section{Figure 2B}
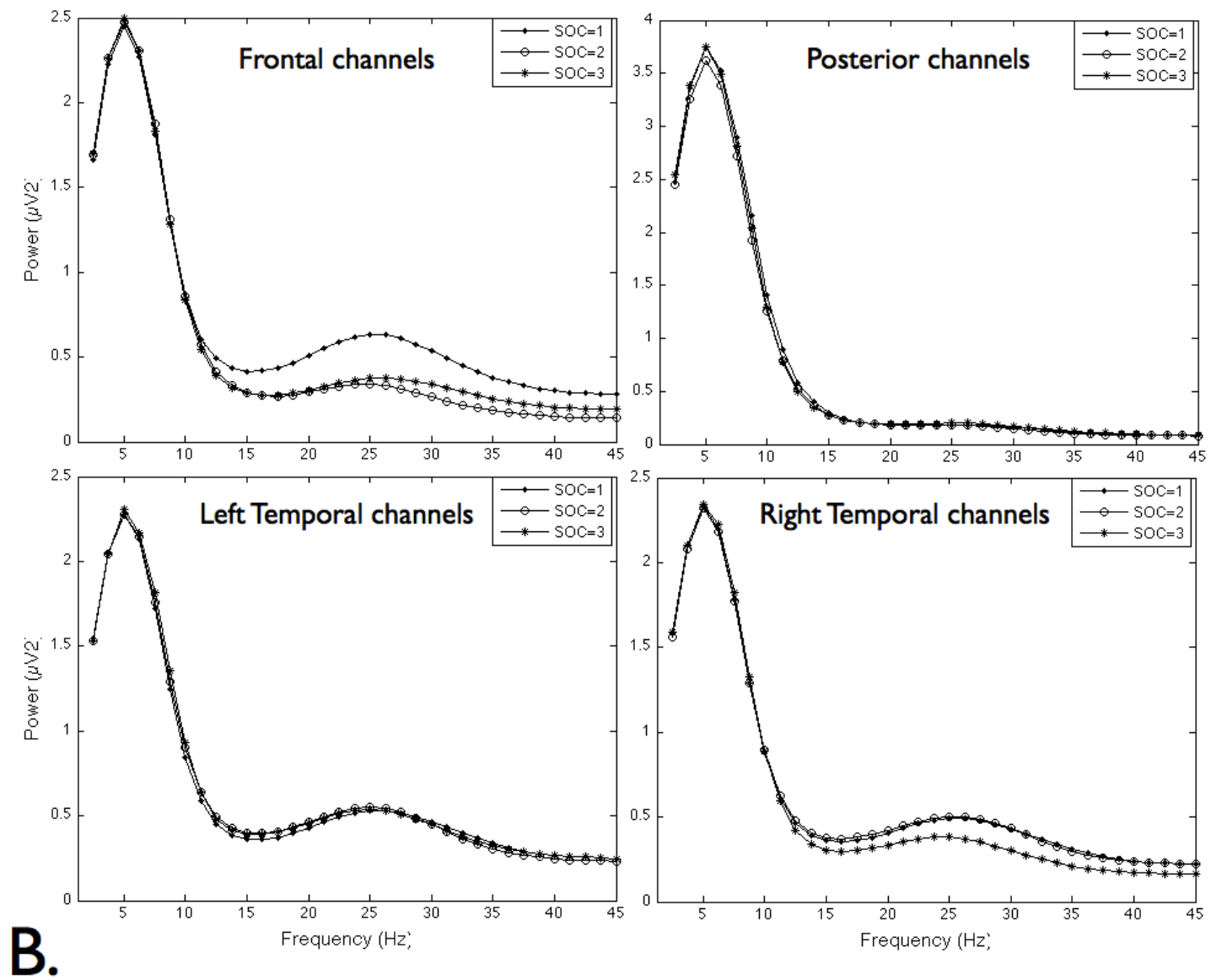
Figure 3A

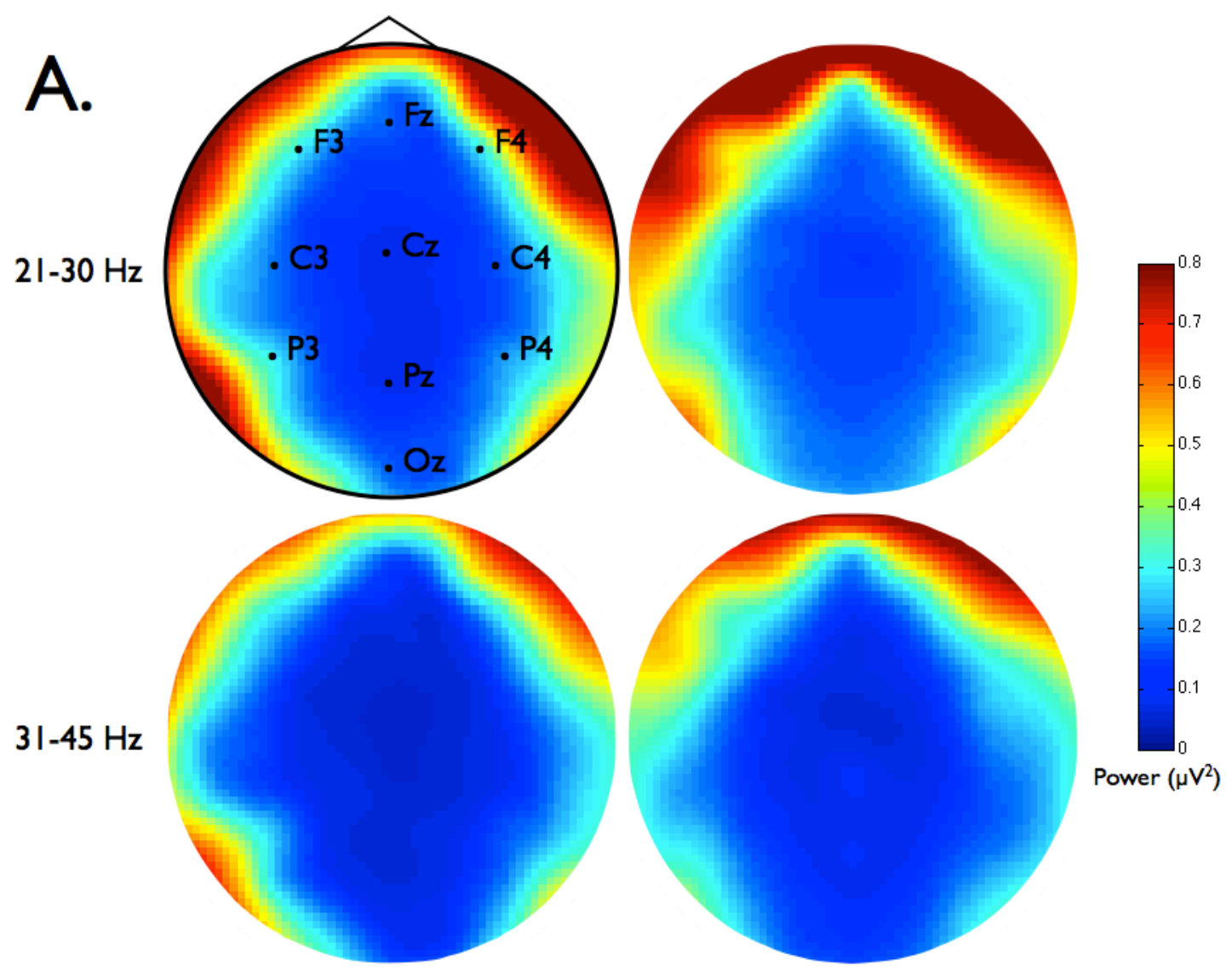

Low income

High income 
Figure 3B

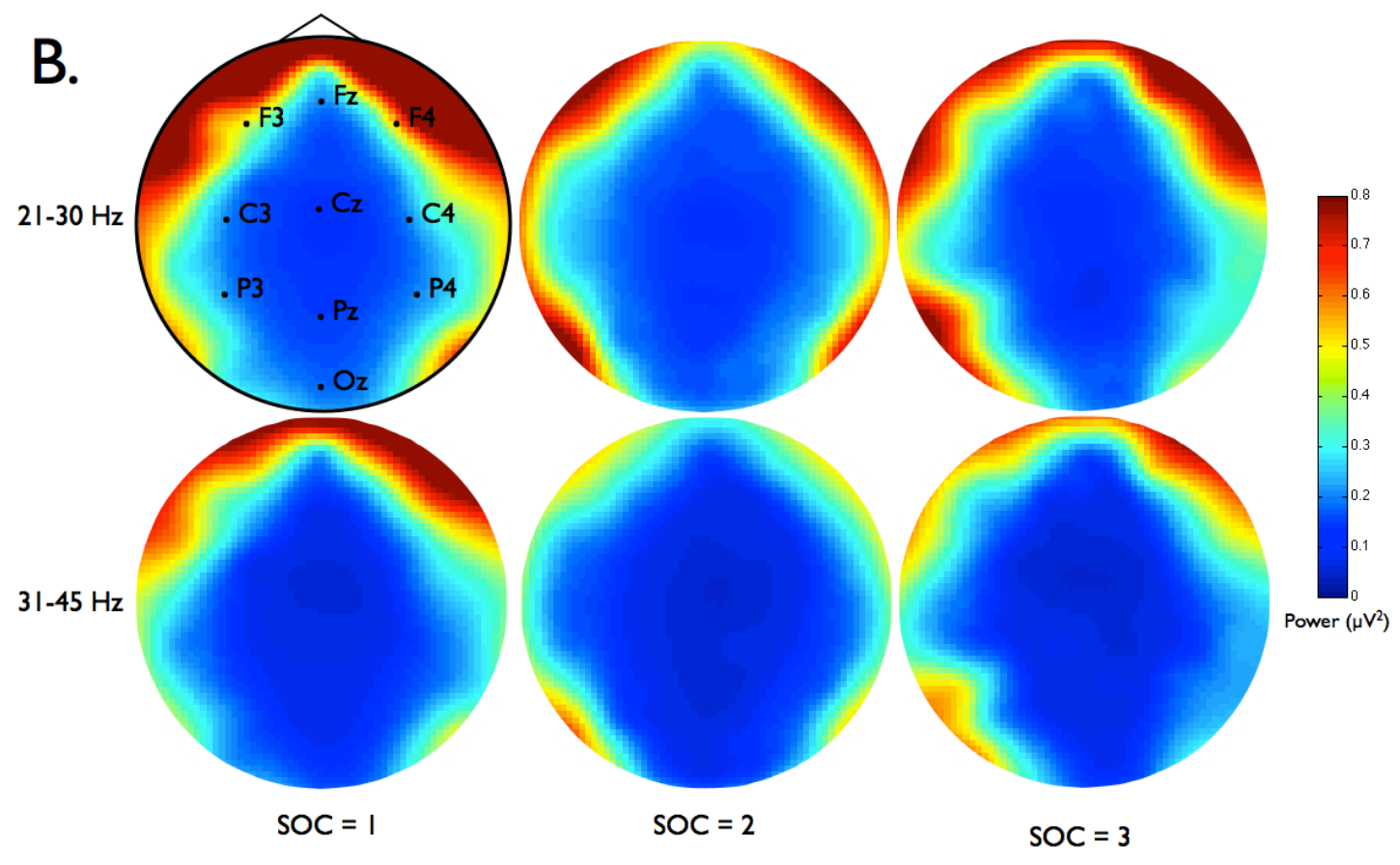

